\title{
The Effect of Nitrogen Gas Flushing on Intermediate Products Formation in Acidogenic Stage of Anaerobic Process of Cocoa Sweatings
}

\author{
Mindriany Syafila, Marisa Handajani \& Adearty Prayascitra \\ Research Group on Water and Wastewater Engineering, \\ Faculty of Civil and Environmental Engineering, Institute of Technology Bandung \\ Email: mindri@ftsl.itb.ac.id
}

\begin{abstract}
Cocoa is one of Indonesian-main plantation commodities. During the cocoa seed drying process, there are two types of waste that are cocoa pod and cocoa sweating. Since the organic compounds contained in cocoa sweating is high enough, it is possible to anaerobically treat this wastewater in order to recover either intermediate or end products. Preliminary study showed that the existence of $\mathrm{H} 2$ in the reactor would block acetic acid formation. Therefore, the aim of this current experiment was to decrease hydrogen partial pressure by flushing various nitrogen gas flow rate to shift the intermediate products during the cocoa sweating anaerobic treatment. The experiments were carried on a Circulating Bed Reactor (CBR) which contained organic compounds around $100,000 \mathrm{mg} / \mathrm{l} \mathrm{COD}$. Then, the reactor was flushed continuously with nitrogen gas as without flushing, $125 \mathrm{ml} / \mathrm{min}, 500 \mathrm{ml} / \mathrm{min}$ and $750 \mathrm{ml} / \mathrm{min}$. The results show there was a possibility that the introduction of nitrogen gas into the reactor could shift the profile of the intermediate product formation. At lower nitrogen gas flow rate more ethanol was formed than acetate formation, although at higher nitrogen gas flow rate the formation of acetate was still low enough.
\end{abstract}

Keywords: acetate formation; acidogenic stage; anaerobic process; cocoa sweatings.

\section{Introduction}

Cocoa is one of Indonesian-main plantation commodities, which is on the third rank after palm and natural rubber. In 2005, the cocoa production has reached 652,396 tonnes [1]. Indonesia is the third largest country as cocoa producer, behind Ivory Coast and Ghana. The increasing in cocoa production is followed by the amount of its waste. During cocoa beans fermentation prior to drying, there are two types of waste that are cocoa pod and cocoa sweatings.

Cocoa sweatings, the pale yellowish liquid that drains off during cocoa fermentation, is the breakdown product of the mucilage surrounding the fresh cocoa bean, and constitutes about $10 \%$ of the weight of the cocoa fruit [2]. The annual amount of cocoa sweating in Indonesia was predicted around 60,000 kilo liter. The cocoa pulp consists of about $85 \%$ water, $2.7 \%$ pentosans, $0.7 \%$ 
sucrose, $10 \%$ glucose and fructose, $0.6 \%$ protein, $0.7 \%$ acids and $0.8 \%$ inorganic salts [3]. This composition seems to appear in the cocoa sweatings. In dealing with high organic compounds concentration, anaerobic process could be considered as one of potential method.

Mosey considered the hydrogen partial pressure as the key regulatory parameter of the anaerobic digestion of glucose [4]. This influences the redox potential in the liquid phase. The model considers four bacterial groups to participate in the conversion of glucose to carbondioxide and methane. A study on acetate production from lactose also showed that the hydrogen partial pressure had an important role in switching the end products from lactate to acetate [5]. Another study on glucose anaerobic biodegradation showed that attempts to regulate acetogenesis by control of hydrogen partial pressure are partially successful although complete shift of the equilibrium to homoacetic end product does not seem possible due to the microenvironment condition [6]. Therefore, the partial pressure of hydrogen in acidogenic fermentation might regulate the pattern of end products formed from glucose.

An effort has to be carried out in order to minimize the hydrogen partial pressure in the reactor. One of the mechanisms is to prevent the hydrogen formation by introducing an external gas sparging. The experiment result showed by Kim, et al. [7] indicated that the introduction of $\mathrm{N}_{2}$ and $\mathrm{CO}_{2}$ into the reactor would have an effect on $\mathrm{H}_{2}$ formation and the decrease of $\mathrm{H}_{2}$ partial pressure had a beneficial effect on fermentation. Another study showed that at higher $\mathrm{N}_{2}$ sparging rate $\mathrm{H}_{2}$ yield would be more than that without any sparging [8]. Therefore, it seems that the introduction of $\mathrm{N}_{2}$ gas into the bioreactor could regulate the hydrogen partial pressure formation.

Since the organic compounds contained in cocoa sweating is high enough, it is possible to anaerobically treat this wastewater in order to recover either intermediate or end products. Therefore, to investigate the possibility of intermediate product shifting, the hydrogen partial pressure should be lowered. The idea based on preliminary study, which showed that the cocoa sweating wastewater could be used as a substrate for acetic acid production through a biological process. However, the presence of $\mathrm{O}_{2}$ in the reactor affected the acetic acid formation pathway and the existence of $\mathrm{H}_{2}$ in the reactor would block acetic acid formation [9]. Therefore, the aim of this current experiment was to decrease hydrogen partial pressure by flushing various nitrogen gas flow rate in order to shift the intermediate products during the cocoa sweating anaerobic treatment. This intermediate product shifting will lead to high production of cocoa sweating recovery. 
The Effect of Nitrogen Gas Flushing on Intermediate Products131

\section{$2 \quad$ Materials and Methods}

The experiment was carried in a six liter Circulating Bed Reactor (CBR). In the CBR the head space gas was recirculated through a circular half-perforated plate which was placed at the bottom of reactor. The picture of reactor is presented in Figure 1.

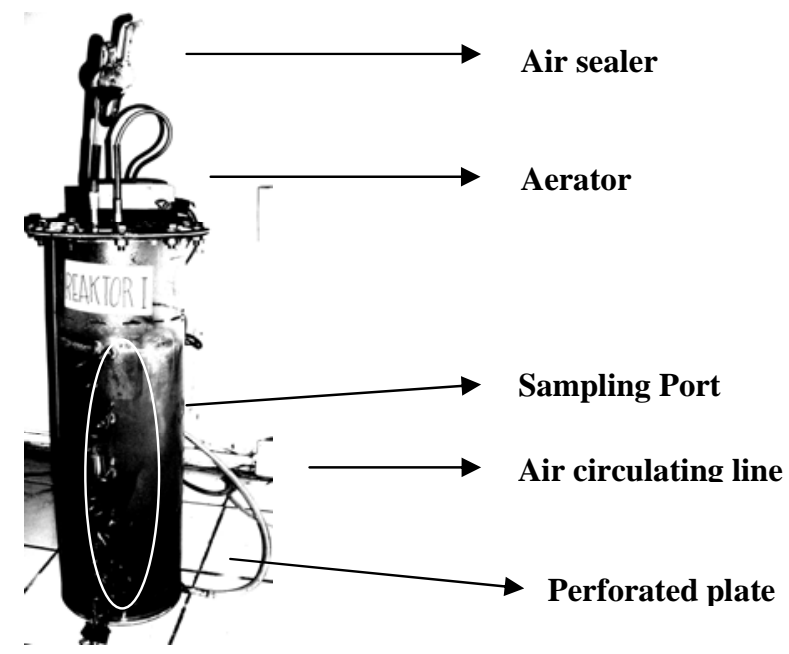

Figure 1 Circulating Bed Reactor.

Each reactor was filled with 4,5 liter of mix medium that consisted of $20 \%(\mathrm{v} / \mathrm{v})$ mixed culture innoculum $(900 \mathrm{ml})$ and $80 \%(\mathrm{v} / \mathrm{v})$ cocoa sweating. COD of this mix liquor was around 100,000 mg/l. The treatment process was observed in 5 days. The concentration of COD, acetic acid were monitored along with the $\mathrm{pH}$ and temperature. The effects of oxygen and hydrogen presence were also observed in the experiment. In order to remove the oxygen in the headspace gas, the reactor was purged with nitrogen gas for 10 minutes prior to the experiment. Then, the reactor was flushed continuously with nitrogen gas to prevent the accumulation of hydrogen gas in the headspace gas. The flow rate of nitrogen gas flushing was varied as $125 \mathrm{ml} / \mathrm{min}, 500 \mathrm{ml} / \mathrm{min}$ and $750 \mathrm{ml} / \mathrm{min}$ and without flushing. The effect of nitrogen gas flushing on the intermediate products, i.e. ethanol, acetic acid and other volatile fatty acid were observed at acidogenic phase of anaerobic process.

\section{$3 \quad$ Results and Discussion}

A fresh wastewater of cocoa sweating was used in this experiment. Therefore, the characteristics could not be controled or predicted. The characteristics of 
cocoa sweating wastewater was analyzed prior to the experiments. It had a high organic material, solid, and low $\mathrm{pH}$. The detail characteristics of cocoa sweating wastewater is presented in Table 1.

Table 1 Characteristics of cocoa sweating wastewater.

\begin{tabular}{clcc}
\hline No. & Parameter & Unit & $\begin{array}{c}\text { Average } \\
\text { Concentration }\end{array}$ \\
\hline 1. & Temperatur & ${ }^{\circ} \mathrm{C}$ & 25 \\
2. & TSS & $\mathrm{mg} / \mathrm{L}$ & 2,844 \\
3. & VSS & $\mathrm{mg} / \mathrm{L}$ & 2,610 \\
4. & pH & & 4.41 \\
5. & BOD & $\mathrm{mg} / \mathrm{L}$ & 19,100 \\
6. & COD & $\mathrm{mg} / \mathrm{L}$ & $109,190.4$ \\
7. & Glucose & $\mathrm{mg} / \mathrm{L}$ & 17,510 \\
8. & Lactic Acid & $\mathrm{mg} / \mathrm{L}$ & 12,310 \\
9. & Acetic Acid & $\mathrm{mg} / \mathrm{L}$ & 8,200 \\
\hline
\end{tabular}

Since the content of organic substance was high as shown as BOD and COD number, the biological process was proven to be more appropriate. Furthermore, The anaerobic process will be more suitable because the wastewater has organic substance concentration more than $4000 \mathrm{mg} / \mathrm{l}$ as COD.

\subsection{Ethanol Formation}

Figure 2 shows the ethanol formation during the anaerobic treatment of cocoa sweatings. The highest ethanol production was obtained from the bioreactor without any nitrogen gas flushing for the rector running period of 3 days and then the concentration would decrease. However, compared to the presence of nitrogen flushing, the ethanol production decreased as the nitrogen gas was introduced to the bioreactor. The lowest formation was achieved at the highest nitrogen gas flushing $(750 \mathrm{ml} / \mathrm{min})$. At higher nitrogen gas flushing there might be the shifting in ethanol pathway which to form other products, or the ethanol was being utilized to form acetate.

Mixed culture used was innoculated from rumen and it has been acclimatized using cocoa sweatings as its main substrate. Therefore, since the microorganisms has not been identified, the influence of the predominant culture performance could cause the shifting of the intermediate product formation. This hypothesis has been tested by Inanc, et al.[10], 1996, which shows that the accumulation of intermediate product, i.e. propionic acid was not caused by high hydrogen partial presure, rather it was a result of a shift in the dominat species of acidogenic populations. However, other works by ValdezVaquez, et al. and Krouwel, et al. [11] show that under certain environmental conditions, acidogenic fermentation shifts to solventagonenic fermentation 
The Effect of Nitrogen Gas Flushing on Intermediate Products133

(production of such as acetone, butanol and ethanol) where $\mathrm{H}_{2}$ productivity decreases or stops. Solventogenesis initiation related to high partial pressures of hydrogen, high organic acids concentrations, and/or low $\mathrm{pH}$.



Figure 2 Ethanol formation during the anerobic treatment of cocoa sweatings.

\subsection{Acetate Formation}

Figure 3 shows that acetate formation increased with the increasing in nitrogen gas flushing rate at the $3^{\text {rd }}$ day . However, the optimum acetate formation rate was achieved at different reactor running time for each nitrogen gas flushing flowrate. Without any nitrogen gas flushing and at the flushing rate of 125 $\mathrm{ml} / \mathrm{min}$ and $500 \mathrm{ml} / \mathrm{min}$, the optimum acetate formation rate was obtained at the $4^{\text {th }}$ day of reactor running time. Whereas, for the nitrogen gas flushing rate of $750 \mathrm{ml} / \mathrm{min}$, it was achieved at the $3^{\text {rd }}$ day of reactor running time. It appears that the more nitrogen gas introduced the reactor, the less time needed to form

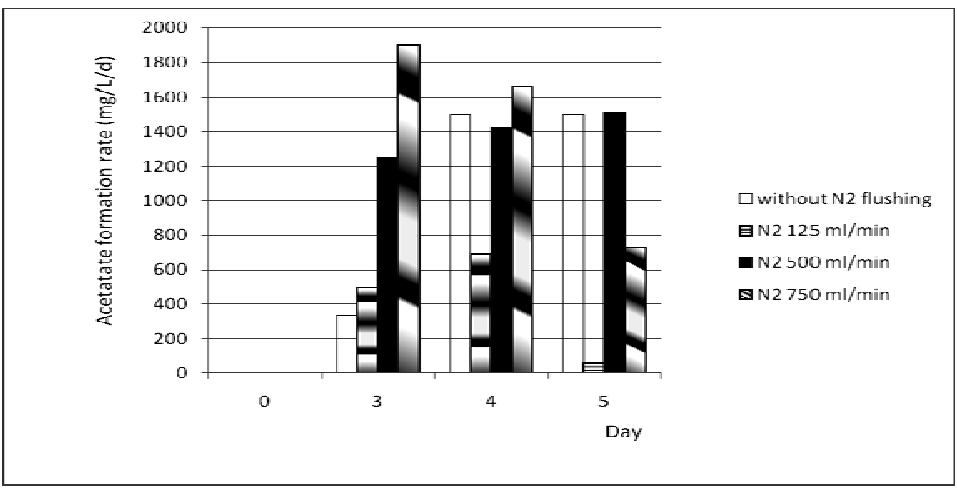

Figure 3 Acetate formation during the anaerobic treatment of cocoa sweating. 
acetate. In this case, the nitrogen gas might succesfully shift away the headspace gas produced that act as be an inhibitor for acetate production.

The effects of hydrogen partial pressure on the fermentative pattern of the anerobic bacteria have been demostrated in previous studies. Chung showed that the quantitative composition of the fermentation products depends on the hydrogen partial pressure [12]. Furthermore, Van Andel et al. demonstrated that sparging a pure culture of Clostridium butyricum with nitrogen increased the acetate production [12].

\subsection{Other Volatile Fatty Acids (VFA) Formation}

As mentioned before the cocoa pulp consists of about $85 \%$ water, $2.7 \%$ pentosans, $0.7 \%$ sucrose, $10 \%$ glucose and fructose, $0.6 \%$ protein, $0.7 \%$ acids and $0.8 \%$ inorganic salts [3]. This composition seems to appear in the cocoa sweatings. Therefore, anaerobic biodegradation of cocoa sweating would follow the common biodegradtion pathway where volatile fatty acid, other than acetate,

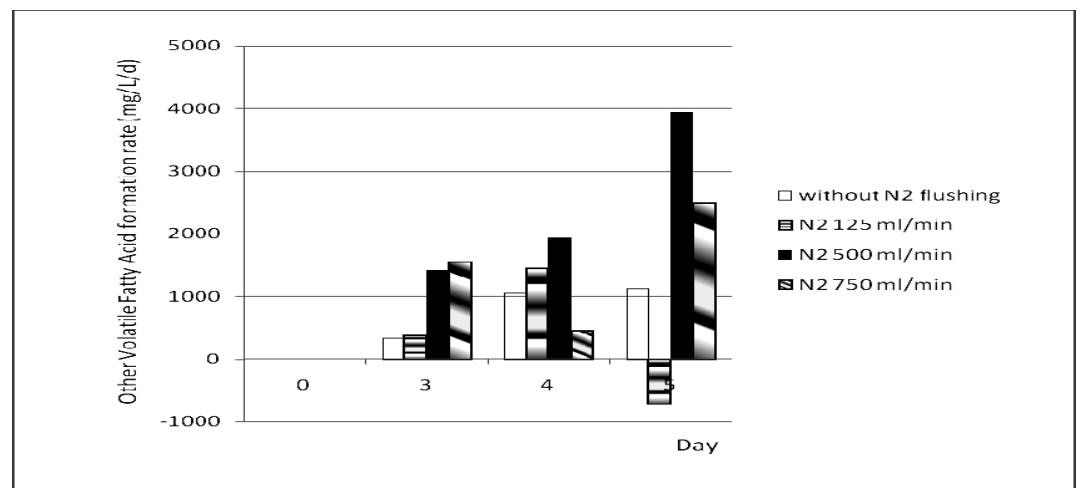

Figure 4 Other volatile fatty acids (VFA) formation during the anaerobic treatment of cocoa sweating.

would be produced. The formation rate of other volatile fatty acids (VFA) is shown in Figure 4. The VFA tended to increase during 5 days of bioreactor running. The highest formation rate obtained at nitrogen gas flushing of 500 $\mathrm{ml} / \mathrm{min}$ and the lowest one was at $125 \mathrm{ml} / \mathrm{min}$. At low nitrogen gas flushing, the anaerobic process couldstill in the acidogenic phase where the intermediate products other than acetate were formed. Considering that the acidogenic bacteria follow the glycolytic metabolic pathway, the factor that regulates the relative amounts of fatty acid generation is the hydrogen partial pressure [4]. The lower nitrogen gas flushing rate, the higher hydrogen partial pressure and it would be thermodynamically favoured to form other fatty acids. However, there 
The Effect of Nitrogen Gas Flushing on Intermediate Products135

was an anomaly during the nitrogen gas flushing of $500 \mathrm{ml} / \mathrm{min}$. This phenomenon appears in three replication of the experiment.

\subsection{The Intermediate Products Formation Profile}

The overall performance in formation of the intermediate products during the anaerobic treatment of cocoa sweating is shown in Figure 5. Apart from the acidogenic bacteria, the flushing of nitrogen gas also influences the formation of the intermediate products. The results showed that nitrogen gas flushing could shift the pathway of the formation of ethanol, other volatile fatty acids and acetate. The more nitrogen gas introduced to the reactor, the more the pathway shift to produce acetate rather than other products. However, the acetate production in the reactor without any nitrogen gas flushing was higher than at the lowest nitrogen gas flushing rate due to the possibility of the oxygen gas presence in the reactor which could lead to the TCA cycle under aerobic condition.



Figure 5 The overall performance of the intermediate product formation of cocoa sweatings anaerobic treatment.

\section{Conclusions}

During the anaerobic treatment process of cocoa sweating, the nitrogen gas flushing could shift the pathway of the intermediate product formation at the acidogenic phase. However, the results were not optimal enough since the acetate formation was still low.

\section{References}

[1] Direktorat Jenderal Perkebunan (Ditjenbun), Road Map Kakao 20052025. Departemen Pertanian. Jakarta, 2006. 
[2] Buamah, R., Dzogbefia, V.P. \& Oldham, J.H., Pure yeast culture fermentation of cocoa (Theobroma cacao L): effect on yield of sweatings and cocoa bean qual, World Journal of Microbiology and Biotechnology, 13(4), 457-462, 1997.

[3] Thompson, S.S., Miller, K.B. \& Lopez, A.S., Cocoa and Coffee, in Doyle, M.P., Beuchat, L.R. \& Montville, T.J., (eds.), Food Microbiology: fundamentals and frontiers, ASM Press, Washington D.C., pp. 721-733, 2001.

[4] Lyberatos, G. \& Skiadas, I.V., Modelling of anaerobic digestion - a review, Global Nest Int. J, 1(2), 63-76, 1999.

[5] Collet, C., Gaudard, O., Peringer, P. \& Schwitzguebel, Jean-Paul, Acetate production from lactose by Clostridium thermolacticum and hydrogenscavenging microorganisms in continuous culture-Effect of hydrogen partial pressure, Journal of Biotechnology, 118(3), 328-338, August 2005.

[6] Fynn, G. \& Syafila, M., Hydogen regulation of acetogenesis from glucose by freely suspended and immobilised acidogenic cells in continuous culture, Biotechnology Letters, ISSN 0141-5492, 12(8), 621-626, August 1990.

[7] Kim, Dong-Hoon., Han, Sun-Kee., Kim, Sang-Hyoun \& Shin, Hang-Sik, Effect of gas sparging on continuous fermentative hydrogen production, International Journal of Hydrogen Energy, 31(15), 2158-2169, December 2006.

[8] Kraemer, Jeremy T. \& Bagley, David M., Optimisation and design of nitrogen-sparged fermentative hydrogen production biorectors, International Journal of Hydrogen Energy, 33(22), 6558-6565, November 2008.

[9] Handajani, M., Syafila, M. \& Bilqies, M., The acetic acid formation as intermediate compound from acidogenesis process of cocoa sweatings for recovery purpose, Proc. the 6th International Symposium on Southeast Asian Water Environment, pp. 222-225, Bandung, 29-31 Oktober 2008.

[10] Inanc, B., Matsui, S. \& Ide, S., Propionic acid accumulations and controlling factors in anaerobic treatment of carbohydrate: effects of $\mathrm{H} 2$ and pH, Water Sci.Technol., 34(5), 317-325, 1996.

[11] Valdez-Vazquez, I., rios-Leal, E., Carmona-martinez, A., Munoz-Paez, K.M. \& Poggi-Varaldo, H.M., Improvement of biohydrogen production from solid wastes by intermittent venting and gas flushing of batch reactors headspace, Environ. Sci. Technol., 40(10), 3409-3415, 2006.

[12] Alshiyab, H.S., Kalil, M.S., Hamid, A.A. \& Wan Yusoff, W.M., Improvement of biohydrogen production under increased the reactor size by C.acetobutylicum NCIMB 13357, American J. Environ Sci., 5(1), 3340, 2009. 